DOI: $10.2478 / \mathrm{v} 10129-011-0005-2$

N. Sabaghnia ${ }^{1}$, H. Dehghani ${ }^{*}$, B. Alizadeh ${ }^{2}$, M. Mohghaddam ${ }^{3}$

\author{
'Department of Plant Breeding, Faculty of Agriculture, Tarbiat Modares University, Tehran, Iran; \\ ${ }^{2}$ Seed and Plant Improvement Research Institute, Karaj, Iran; ${ }^{3}$ Department of Agronomy \\ and Plant Breeding, Faculty of Agriculture, Tabriz University, Tabriz, Iran; \\ * - corresponding author

\section{ANALYSIS ON GENETIC CONTRIBUTION OF SOME TRAITS \\ TO SEED YIELD IN RAPESEED BY ADDITIVE-DOMINANCE GENETIC METHOD OF MIXED MODEL}

\begin{abstract}
A genetic model is developed with additive, dominance and genotype $\times$ environment interaction effects for the progeny from a diallel mating design. To uncover the genetic contributions of some traits of rapeseed to seed yield and find indicator traits for indirect selection, multivariable conditional analysis was conducted based on this method. Therefore, an experiment was conducted to estimate genetic parameters using a half diallel of nine international rapeseed cultivars. The $36 \mathrm{~F} 1$ hybrids, the parents and four additional cultivars were planted in the breeding nurseries in 2008 and 2009. Several traits including number of pods per plant (NPP), pod length (LP), height of the first pod (HFP), height of the first lateral branch (HFB), stem diameter (SD), days of flowering period (FP), days to physiological maturity (DPM) and seed yield were recorded. The genetic variance component $\left(\mathrm{V}_{\mathrm{D} \times \mathrm{Y}}\right)$ was significant for all the studied traits but the genetic variance component $\left(\mathrm{V}_{\mathrm{A}}\right)$ was significant for NPP, HFB, HFP, DPM and SY traits and the genetic variance component $\left(\mathrm{V}_{\mathrm{D}}\right)$ was significant for HFB, HFP, LP and FP traits. There was significant positive phenotypic correlation $\left(\mathrm{r}_{\wedge}\right)$ between seed yield with NPP and HFP and there was significant positive dominance $\times$ year interaction correlation $\left(\mathrm{r}_{\mathrm{D} \times \mathrm{Y}}\right)$ between seed yield with NPP and DPM while there was significant negative dominance $\times$ year interaction correlation $\left(\mathrm{r}_{\mathrm{D} \times \mathrm{Y}}\right)$ between seed yield with HFB, LP and FP. There were significantly positive additive effects of SY for two parents Orient and Talaye. Finally according to additive-dominance genetic model and conditional genetic effects, the genotypes Talaye proved good general combiner for seed yield improvement and crosses $4 \times 8$ (Orient $\times$ Talaye), $7 \times 8$ (Opera $\times$ Talaye) were found the best specific combiner for all the studied traits.
\end{abstract}

Keywords: additive $\times$ year interaction; Brassica napus L.; diallel; dominance $\times$ year interaction

\title{
INTRODUCTION
}

There are many genetic models which have been developed based on the analysis of variance (ANOVA) approaches. Some of these models, such as North Carolina (NC) designs (Hallauer and Miranda 1981) and diallel designs (Hayman, 1954; Griffing 1956; Gardner and Eberhart, 1966) are still widely

Communicated by Henryk J. Czembor 
used by plant breeders for genetic improving of different crops. Although using of the above mentioned procedures (ANOVA approaches) results in good achievements in breeding progress of many crops in last decades, but these methods have some deficiencies in analyzing genetic models with unbalanced data, or non-integer values of coefficients, or correlated random factors (Zhu and Weir, 1994b; 1998). Therefore, the further development of quantitative genetics in plant breeding has been restrained in some ways by its prevailing dependency on ANOVA-based approaches.

Phenotypic variation of quantitative traits cannot only due to the genetic effect $(G)$ and environment effect $(E)$ with genetic by environment $(G \times E)$ interaction effects can be other important causes of this variation. The statistical analysis of both effects was practically impossible for some genetic models with mixed effects. Cockerham (1980) resolved this problem and proposed methodology for constructing general genetic models and set up fundamental principle in developing many kinds of complicated genetic models. Mixed linear models which developed by statisticians (Hartley and Rao, 1967; Rao, 1970; Miller, 1974) can be applied in quantitative genetics and classic plant breeding methodology. These procedures overcome the shortcomings of ANOVA methods for handling unbalanced data and complicated models (Rao, 1971). In analyzing seed oil content of cotton, Zhu and Weir (1994a), proposed a genetic model of diallel crosses based on the mixed models for estimating variance and covariance components of cytoplasmic, maternal additive and dominance effects, as well as direct additive and dominance effects. Development of such mixed linear model and its application in plant breeding will create enormous challenges for geneticists and breeders in dealing with complicated genetic problems.

Zhu and Weir (1994a) used minimum norm quadratic unbiased estimation (MINQUE) method to estimate the variance components for single trait and covariance components for multiple traits of these random factors, and also linear unbiased prediction (LUP) method is used to predict the random effects of these random factors. The random factors including additive effect, dominance effect, paternal effect, and environment effect etc. For the analysis of the phenotypic variation of quantitative traits, Abderrahmane and Zhu (2001) centered particularly on the influence of the environment and on the interaction between genetic and environment effects. They declared that an understanding of the inheritance of these differences is of fundamental significance in the study of evolution and in the application of genetics to animals and plant breeding (Abderrahmane and Zhu, 2001).

Iran has been facing a chronic shortage of edible oil; a large quantity of edible oil is imported annually from other countries to fill the gap between local production and consumption. Interest in growing winter rapeseed (Brassica napus L) in Iran is increasing due to its potential returns relative to other oilseed 
crops. Rapeseed is an annual crop, well adapted to cold climate, with a tap root system and many lateral roots concentrated in the shallow subsurface soil and is predominantly grown in the winter in regions of Iran where the annual average rainfall is 300 to $400 \mathrm{~mm}$ (Dehghani et al., 2008). Iran has had an important rapeseed breeding program in recent years, supported by the Seed and Plant Improvement Institute (SPII). Increasing the genetic potential of yield, tolerance to biotic and abiotic stresses and early maturity are important objective of rapeseed breeding programs in Iran and other countries.

The objectives of this investigation were to ascertain genetic contribution of some yield component traits to seed yield of rapeseed by additive-dominance method of (Zhu and Weir, 1996), multivariable conditional analysis (Atchley and Zhu, 1997) and find important traits influencing seed yield in the rapeseed, which may be useful in indirect selection for breeding high yielding cultivars.

\section{MATERIALS AND METHODS}

\section{Plant materials and experiments}

The nine rapeseed parental genotypes selected for study were seven international cultivars (Fornax, Colvert, SLM046, Okapi, Orient, Opera and Modena) from France, Denmark, Sweden and Germany countries and two Iranian cultivars (Zarfam and Talaye) from Iran's Seed and Plant Improvement Institute (SPII), which had previously been introduced for commercial release in Iran. a diallel cross, without reciprocals, between all the parents was carried out in field to obtain 36 bi-parental combinations in the 2007 season. The experiments were installed in a field at the Tarbiat Modares University experimental field near the city of Tehran across two growing seasons (2008 and 2009). In these seasons, two sets of material consisting of parents, their $36 \mathrm{~F}_{1}$ hybrids and four control genotypes including Hayola 401, RGS003, Licord and Opera genotypes were sown.

The experiments were accomplished in layout of a simple lattice design with two replications. To avoid plant stand failure each hill-plot was sown with three seeds of the respective genotype and shortly after emergence the plantlets were randomly thinned to one plant per hill-plot. Plot size was $7.2 \mathrm{~m}^{2}$, consisting of 8 rows $3 \mathrm{~m}$ length of rapeseed with $30-\mathrm{cm}$ between-row and $5-\mathrm{cm}$ within-row spacing. The experiment in each year received all recommended agricultural practices to ensure normal rapeseed plant development, including liming, manual weeding and irrigation. Each year, soil preparation was done by mould board plowing and disk. Fertilizer application was $40 \mathrm{~kg} \mathrm{~N} \times \mathrm{ha}^{-1}$ and $70 \mathrm{~kg} \mathrm{P}_{2} \mathrm{O}_{5} \times \mathrm{ha}^{-1}$ at planting and $30 \mathrm{~kg}$ $\mathrm{N} \times \mathrm{ha}^{-1}$ at stem elongation stage.

At the time of harvest, in order to control boarder effects, plants from the sides of each plot and two rows were removed and harvest area was decreed to 
$4.5 \mathrm{~m}^{2}$. Although many different traits were measured and available for analysis but only eight important traits are offered in this paper. To measure yield components including number of pods per plant (NPP), pod length (LP), height of the first pod (HFP), height of the first lateral branch (HFB), stem diameter (SD); ten random plants were harvested from each plot at the time of maturity. Seed yield was measured at physiological maturity and yield was adjusted to $12.5 \%$ seed moisture content. Days of flowering period (FP) and days to physiological maturity (DPM) were recorded.

\section{Statistical methods}

A genetic model including additive and dominance effects (Zhu et al., 1993) and their interaction effects with year (Zhu, 1996) was employed to study the developmental inheritance of seed yield and related traits in rapeseed across two years conditions. According to the model, unconditional genetic analysis was conducted based on phenotypic values, which can be partitioned as:

$$
y_{i j k l}=\mu+Y_{i}+A_{j}+A_{k}+D_{j k}+A Y_{i j}+A Y_{i l}+D Y_{i j k}+B_{l(y)}+e_{i j k l}
$$

where $y_{i j k l}$ is the yield of entry $j$ in tester $k$ for replicate $l$ and year $i$; $\mu$ is the grand mean; $Y i$ is the $i$ th year effect; $A j$ is the additive effect of parent $j ; A k$ is the additive effect of parent $k$; Djk is the dominance effect of parent $k$ and parent $j$; $A Y i j$ and $A Y i k$ the additive $\times$ year interaction effects of parent $k$ and parent $j$; $D Y i j K$ the dominance $\times$ year interaction effects of parent $k$ and parent $j ; b l(i)$ is the block effect and eijkl is the residual effect. All of the genetic effects in the model were random effects.

The phenotypic values seed yield conditional on phenotypic values of the other triats can be partitioned through procedure of Zhu (1995). For conditional analysis, SY $\mid \mathrm{T}$ represents the seed yield given the other traits (Shi et al., 2003) which is computed for further calculating conditional variance components and conditional genetic effects. The proportion of these parameters can uncover the contribution of genetic variances without the influence of the given component trait on the target trait or seed yield. Different correlation coefficients between various traits were calculated for the phenotypic correlation coefficient $\left(r_{\mathrm{ph}}\right)$, correlation coefficients due to additive effect $\left(r_{\mathrm{A}}\right)$, correlation coefficients due to dominance effect $\left(r_{\mathrm{D}}\right)$, and the corresponding $\mathrm{G} \times \mathrm{Y}$ interaction correlation coefficients $\left(r_{\mathrm{A} \times \mathrm{Y}}\right.$ and $\left.r_{\mathrm{D} \times \mathrm{Y}}\right)$.

To test the response of genotypes to seed yield traits we performed analysis of variance (ANOVA) using the Statistical Analysis System (SAS) software release 6.11 (SAS 1996). Both unconditional and conditional variances were estimated by the MINQUE method (Zhu 1992; Zhu and Weir, 1994). The jackknife method was applied to estimate standard errors of estimated seed yield genetic variances and correlation coefficients (Miller, 
1974; Zhu and Weir, 1994). a t-test following jackknifing was employed for testing the significance of genetic parameters. The genetic effects of the seven parents were predicted using the adjusted unbiased prediction (AUP) method (Zhu and Weir, 1996; Wu et al., 2006). All of the mentioned statistical analysis was done by QGAStation software which is developed by Chen and Zhu (2003) and up-to-date information on QGA Station is available at http://ibi.zju.edu.cn/software/qga/index.htm.

\section{RESULTS}

\section{Analysis of variance and variance components}

The analysis of variance for parental and F1 generation in seed yield and related traits are done and the results showed that there was variation between parents and F1 generation regarding the eight traits (data are not shown). Both the effects of year and genotype $\times$ year interaction were significant, suggesting that these traits were influenced by the year and also there could be a certain degree of heterosis in the $\mathrm{F}_{1}$ genotypes.

Table 1

Estimated phenotypic variance, genetic variance components and their proportion of variance for seven agronomic traits and seed yield (SY) in rapeseed

\begin{tabular}{|c|c|c|c|c|c|c|c|c|}
\hline GP & MPP & HFE & HFP & LP & SD & FP & DPM & $s \mathrm{Y}$ \\
\hline $\mathrm{V}_{\mathrm{A}}$ & $33.4956^{-1}$ & $1.9993^{++}$ & $1.1804^{t *}$ & 西 & 0 & $00000^{m}$ & $0.3261^{ \pm+}$ & $22413.35^{-*}$ \\
\hline$V_{\mathrm{a}}$ & $0.0000^{\mathrm{m}}$ & $4.7122^{+}$ & $3.6455^{t+}$ & $00929^{\circ-}$ & $0.0000^{\mathrm{ng}}$ & $1.4407^{+\circ}$ & $0.0000^{m}$ & $0,0000^{n x}$ \\
\hline$V_{i n-\infty}$ & $0.0000^{\mathrm{mit}}$ & $0.0000^{\mathrm{m}}$ & $0.0000^{\mathrm{nn}}$ & $0.0000^{\mathrm{mm}}$ & $0.0000^{\mathrm{nu}}$ & $0.0000^{1 \mathrm{H}}$ & $0.0000^{\mathrm{mt}}$ & $0.0000^{\mathrm{ng}}$ \\
\hline $\mathrm{V}_{\mathrm{D}=\mathrm{y}}$ & $2130878^{F}$ & $16.7543^{\prime+}$ & $6.7614^{7 *}$ & $00700^{-\infty}$ & $0.0193^{-}$ & $158539^{\circ+}$ & $4.0580^{=*}$ & $303629.79^{=7}$ \\
\hline$v_{\mathrm{l}}$ & $2436355^{4+}$ & $80.2222^{+}$ & $77.8827^{* *}$ & $0.1117^{+*}$ & $0.0212^{+}$ & $30.4278^{-*}$ & $11.4167^{* *}$ & $281723.66^{\circ+}$ \\
\hline$V_{\text {rh }}$ & 4902189 & 103.5881 & 89.4699 & 02746 & 0.0404 & 47.7223 & 15.8007 & 607766.80 \\
\hline \multicolumn{9}{|c|}{ PV $\ddagger$} \\
\hline $\mathrm{V}_{h} / N_{\mathrm{pht}}$ & 6.83 & 1.93 & 1.32 & 0.00 & 0.00 & 0.00 & 2.06 & 369 \\
\hline $\mathrm{v}_{\mathrm{a}} / N_{\mathrm{ph}}$ & 0.00 & 4.54 & 4.07 & 33.81 & 0.00 & 3.02 & 0.00 & 000 \\
\hline $\mathrm{v}_{\mathrm{A} \rightarrow \mathrm{r}} N_{\mathrm{ph}}$ & 000 & 0.00 & 0.00 & 0.00 & 0.00 & 0.00 & 0.00 & 0.00 \\
\hline$V_{\mathrm{a}-\mathrm{r}} N_{\mathrm{pht}}$ & 43.47 & 16.16 & 7.56 & 25.51 & 47.65 & 33.22 & 25.68 & 4996 \\
\hline
\end{tabular}

$\mathrm{V}_{\mathrm{A}}$, additive variance; $\mathrm{V}_{\mathrm{D}}$, dominance variance; $\mathrm{V}_{\mathrm{A}} \times \mathrm{YE}$, additive $\times$ year interaction variance; $\mathrm{V}_{\mathrm{D} \times \mathrm{Y}}$ dominance $\times$ year interaction variance; $\mathrm{V}_{\mathrm{R}}$, residual variance and $\mathrm{V}_{\mathrm{ph}}$, phenotypic variance; $* *$, ${ }^{*}$ and ${ }_{\mathrm{ns}} \times \mathrm{r}_{\mathrm{A}}$ respectively, significant at $1 \%$ and $5 \%$ probability level and non-significant; $\uparrow$ GP; Genetic parameters; $\$$ PV; Proportion of variance

The estimated phenotypic variance and genetic variance components were presented in Table 1 for seven measured traits and seed yield. The genetic variance component $\left(\mathrm{V}_{\mathrm{D} \times \mathrm{Y}}\right)$ was significant for all the studied traits. It was suggested that these traits consist on NPP, SD, FP and SY were controlled by 
dominance $\times$ year interaction effect. It was indicated, by high ratios of dominance $\times$ year interaction variance $\left(\mathrm{V}_{\mathrm{D} \times \mathrm{Y}} / \mathrm{V}_{\mathrm{ph}}\right)$ for NPP, SD, FP and SY traits indicated that utilization of heterosis could be feasible in special environments. The additive genetic variance component $\left(\mathrm{V}_{\mathrm{A}}\right)$ was significant for NPP, HFB, HFP, DPM and SY traits and the genetic variance component $\left(\mathrm{V}_{\mathrm{D}}\right)$ was significant for HFB, HFP, LP and FP traits. It was indicated, by low ratios of additive genetic variance to phenotypic variance $\left(\mathrm{V}_{\mathrm{A}} / \mathrm{V}_{\mathrm{ph}}\right)$ for NPP $(6.83 \%)$, HFB (1.93\%), HFP (1.32\%), DPM (2.06\%) and SY (3.69\%), that the selection in late generation could obtain apparent genetic gain for these traits (Table 1).

Finally, it was suggested that the two agronomic traits (HFB and HFP) were controlled by genetic main effects (additive and dominance) as well as genotype $\times$ year interaction effects. Height to the first lateral branch is an important trait, especially during harvest season, which makes rapeseed breeders eager for developing high yielded cultivars with desirable plant architecture (MarjanovicJeromela et al., 2008). Regarding this trait, breeding to favorable seed yield by high values HFB could be useful during harvest season. Also, it was suggested that the two agronomic traits (NPP, DPM and SY) were controlled by additive genetic main effect as well as genotype $\times$ year interaction effects. Thus the rustles of this research indicated this fact that the $\mathrm{G} \times \mathrm{Y}$ interactions are not avoidable in agriculture investigations (Allard and Bradshaw, 1964; Yan and Kang, 2003). The variation in the performance of the genotypes across environments can be ascribed to significant changes in the GCAs of the parents and SCAs of crosses across the environments.

\section{Phenotypic and genetic correlation between traits}

Estimated correlation coefficients of genetic components between seed yield and other measured traits were presented in Table 2. There was significant positive phenotypic correlation $\left(r_{\mathrm{A}}\right)$ between seed yield with NPP and HFP and there was significant positive dominance $\times$ year interaction correlation $\left(r_{\mathrm{D} \times \mathrm{Y}}\right)$ between seed yield with NPP and DPM while there was significant negative dominance $\times$ year interaction correlation $\left(r_{\mathrm{D} \times \mathrm{Y}}\right)$ between seed yield with HFB, LP and FP. Tak (1976) and Yadav and Singh (1996) concluded that the strongest effect of NPP on seed yield in rapeseed. There was no dominance correlation $\left(r_{\mathrm{D}}\right)$ and additive $\times$ year interaction correlation $\left(r_{\mathrm{A} \times \mathrm{Y}}\right)$ between seed yield and seven agronomic traits. Also there was no high positive or negative correlation between seed yield and the other traits (Table 2). Partial correlation analysis of some researches (Han and Liu, 1993; Li et al., 2001) showed that number of pods per plant was positively correlated with seed yield but on the contrary, length of pod was negatively correlated with seed yield. 
Analysis on genetic contribution of some traits to seed vield in rapeseed by

\begin{tabular}{|c|c|c|c|c|c|c|c|}
\hline \multicolumn{8}{|c|}{$\begin{array}{l}\text { Estimated correlation coefficient percents of genetics components between seed yield (SY) } \\
\text { and seven agronomic traits and seed yield (SY) in rapeseed }\end{array}$} \\
\hline Parameters: & NPP $w s Y$ & HFB w. SY & HFP w $\mathrm{SY}$ & LP w SY & SD $\% S Y$ & FP $w S Y$ & DPM $w S Y$ \\
\hline$r_{A}$ & $3766^{\circ}$ & 425 & $96.70^{4+}$ & 0 & 0.00 & 0 & 16.16 \\
\hline$r_{a}$ & 0 & סूDِ & סِסِ, סِ & סूסِ & 0 & סַס & סِסַ, סِ \\
\hline$r_{B \times y}$ & 0.00 & 0.00 & 0.00 & 0.00 & 0.00 & 0.00 & 0.00 \\
\hline$r_{\mathrm{D} N \mathrm{Y}}$ & $63.83^{7+}$ & $-5156^{+}$ & 17.89 & $-54.73^{F+}$ & -7.65 & $-57.27^{4+4}$ & $40.42^{+F}$ \\
\hline$r_{\text {ph }}$ & 18.96 & -17.43 & .8 .32 & -0.06 & 2.28 & -11.39 & 13.79 \\
\hline
\end{tabular}

$r_{A}$, additive correlation; $r_{D}$, dominance correlation; $r_{A \times Y}$, additive $\times$ year interaction correlation; $r_{D \times Y}$ dominance; $\times$ year interaction correlation and $\mathrm{r}_{\mathrm{ph}}$, phenotypic correlation; $* *$ and $*$ respectively, significant at $1 \%$ and $5 \%$ probability level

Correlations between yield and yield-determining traits have been repeatedly analyzed in rapeseed by different researchers (Olsson, 1960; Richards and Thurling, 1979; Lefortbuson and Dattee, 1985; Ozer et al., 1999; Ivanovsk et al., 2007). Also, Allard and Bradshaw, (1964) and Cooper and Byth (1996) explained that the larger the degree of genotype by environment interaction, the more dissimilar the genetic systems controlling the physiological processes conferring adaptation to different environments. In other word, the significance of dominance $\times$ year interaction correlation, indicating that all of the studied traits were sensitive to environmental conditions and that data from additional environments or seasons would make parameters effects more precise. The cause of no significant phenotypic correlation between some traits and seed yield was due to the fact of positive correlation for genetic main effects $\left(r_{\mathrm{A}}\right)$ but negative correlation for genotype $\times$ year interaction effects $\left(r_{\mathrm{D} \times \mathrm{Y}}\right)$ between these traits, although some of these correlations were not significant.

\section{Phenotypic and genetic contribution ratios of traits to SY}

The ratios of genetic contribution for different traits due to seed yield are summarized in Table 3. Although there was no significant contribution of genetic main effects of all traits to SY, there was large contribution of dominance $\times$ year interaction. It was suggested that there was need for considering indirect selection in specific environments on the agronomic traits of $F 1$ crosses. Also there was no significant contribution of additive $\times$ year interaction. It was implied that indirect selection on the agronomic traits could not obtain improvement for seed yield even in specific environments. The phenotypic contribution ratios were significant for all the seven agronomic studied traits. It was revealed that the phenotypic variation of seed was significantly contributed by these agronomic traits (Table 3 ). 


\begin{tabular}{|c|c|c|c|c|c|c|c|}
\hline Parameters & WPP Us SY & HFB $\Psi, S Y$ & HFP US $S Y$ & LP w SY & SD $v S_{S Y}$ & $\mathrm{FP} \psi s Y$ & DPM \\
\hline$C R_{A}$ & 1.93 & 393 & 3.75 & 3.01 & 3.77 & 3.17 & 3.73 \\
\hline$C R_{\square}$ & 000 & 0 & Dō & 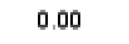 & סू. & 0 & 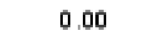 \\
\hline$C R_{A x Y}$ & 0.00 & 000 & 0.00 & 0.00 & 0.00 & 0.00 & 0.00 \\
\hline$C R_{\mathrm{IVY}}$ & $43.33^{\circ}$ & $4729^{\circ}$ & $50.49^{*}$ & $46.26^{\circ}$ & $4981^{*}$ & $46.97^{*}$ & $48.46^{*}$ \\
\hline$c R_{\text {ph1 }}$ & $51.45^{+}$ & $57.16^{+*}$ & $60.58^{++}$ & $55.48^{++}$ & $60.67^{+}$ & $56.09^{+4}$ & $58.86^{++}$ \\
\hline
\end{tabular}

CRA, additive contribution ratios; $\mathrm{CR}_{\mathrm{D}}$, dominance contribution ratios; $\mathrm{CR}_{\mathrm{A} \times \mathrm{Y}}$, additive $\times$ year interaction contribution ratios; $\mathrm{CR}_{\mathrm{D} \times \mathrm{Y}}$, dominance $\times$ year interaction contribution ratios and $\mathrm{CR}_{\mathrm{ph}}$, phenotypic contribution ratios; **and * respectively, significant at $1 \%$ and $5 \%$ probability level

Rameah et al. (2003) and Marjanovic-Jeromela et al. (2007), who found that most of the total genetic variability for some of agronomic traits in rapeseed crosses, were due to both additive and non-additive gene effects. Thus, conditional analysis could help to clarify the presence of genetic effects due to new gene expression that could not be detected by unconditional analysis. Significant conditional residual variances showed that the performance of seed yield due to the other traits were also influenced by sampling errors (data are not shown). Similar results for significance conditional residual variances were reported by the other researchers such as Shi et al. (2002) in paddy rice and Zhang et al. (2007) in sponge gourd.

Table 4

Predicted additive effects of seed yield (SY) and contributed additive effects of agronomic trait to $\mathrm{SY}$ in rapeseed

\begin{tabular}{|c|c|c|c|c|c|c|c|c|}
\hline \multirow{2}{*}{ Parents } & \multicolumn{7}{|c|}{ Cortibuted addive iffects of taits to $S Y$} & \multirow{2}{*}{$\$ Y$} \\
\hline & WPP & HFB & HFP & $\mathrm{LP}$ & SD & $\mathrm{FP}$ & DPM & \\
\hline Foumax & .0007 & 0.020 & 0017 & $0.030^{+}$ & $0.024^{*}$ & $0.032^{+}$ & $0.032^{*}$ & -0.464 \\
\hline Okapi & 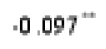 & . $0.09 s^{+1}$ & $0.101^{* 1}$ & " & $-0.06^{* t}$ & $-102^{+10}$ & $=0.09 s^{*}$ & $-0.637^{* t}$ \\
\hline SLMÖ46 & $0.045^{-1}$ & - $0.079^{* *}$ & $0063^{4+}$ & $=0.079^{\circ+}$ & - $0.083^{* *}$ & -0072 & 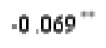 & $-0.860^{* *}$ \\
\hline Orient & 0.006 & 0.028 & 0017 & $0.030^{\circ}$ & $0.046^{*}$ & 0.009 & $0.041^{*}$ & $1.659^{* *}$ \\
\hline Colvert & -0.002 & -0.004 & -0.008 & 0.002 & -0.001 & 0.009 & -0.011 & -0.305 \\
\hline Zurfam & 0005 & .0 .020 & -0019 & -0.011 & -0.009 & -0.017 & -0.004 & $-0.640^{++}$ \\
\hline Opera & $0.093^{+4}$ & $0.099^{* * t}$ & $0092^{\circ+}$ & $0.085^{+1}$ & $0.089^{* *}$ & $0.082^{\circ-}$ & $0.085^{+1}$ & $-0.472^{*}$ \\
\hline Talaye & $0.034^{-1}$ & $0.054^{* *}$ & $0044^{-*}$ & $0.043^{\circ}$ & $0.041^{* *}$ & $0059^{\circ}$ & $0.044^{-4}$ & $2.254^{* *}$ \\
\hline Modena & 0.013 & 0.000 & 0.021 & -0.002 & -0.011 & 0001 & -0.021 & $-0.535^{*}$ \\
\hline
\end{tabular}

$* *$ and $*$ respectively, significant at $1 \%$ and $5 \%$ probability level 
Contributed additive genetic effects of traits to SY

Predicted additive genetic effects of seed yield and contributed additive effects of seven traits to SY were given in Table 4 . There were significantly positive additive effects of SY for two parents (Orient and Talaye). For parent Orient, the positive additive effects of SY resulted mainly from traits SD and DPM while for parent Talaye, the positive additive effects of SY resulted from all studied traits. Having large additive effect of SY and contributed positive additive effects of all agronomic traits to Talaye could serve as a good parent in selection for favorable traits with high SY. The other seven parents had negative additive effects of seed yield, although most of them contributed positive additive effects of the agronomic traits, revealing less importance of additive effects of these traits contributed to seed yield (Table 4). Although we did not find additive genetic effects for the above traits but some researchers emphasized the importance of additive genetic effects for some traits such as NPP and LP in rapeseed (Brandle and McVetty, 1989; Singh et al., 1995; Rameah et al., 2003).

In this study, different values of seed yield were registered and the hybrids had somewhat increased value compared with their parents. Similar results were reported by Pospisil and Mustapic (1995) and Marinkovic (2004). The negative additive effects were mainly due to HFP and FP for Okapi parent, HFB, HFP, LP, SD, FP and DPM for SLM046 and DPM for Modena. There were no significant additive effects of TS for parents Fornax and Colvert. Although LP, SD, FP and DPM had positive contribution to additive effects of SY for Fornax, but none of the measured traits had positive or negative contribution to additive effects of SY for Colvert. However, the seven agronomic traits contributed significant negative additive effects to SY in SLM046 and Okapi. It is possible that the other traits contributed positive additive effects to TS of SLM046 and Okapi.

\section{Contributed dominance effects of traits to $S Y$}

For all $\mathrm{F}_{1}$ crosses, the predicted dominance effects of SY and contributed dominance effects of seven agronomic traits to SY were presented in Table 5. There were positive dominance effects of SY for 16 combinations including $1 \times 3,1 \times 5,1 \times 9,2 \times 3,2 \times 9,3$ $\times 6,4 \times 5,4 \times 6,4 \times 8,4 \times 9,5 \times 7,5 \times 8,6 \times 7,6 \times 8,6 \times 9$ and $7 \times 8$ crosses. The positive dominance effect of SY was resulted from different traits for different crosses but most of the positive dominance effect of SY was resulted mainly from all traits. In contrast, the positive dominance effect of SY was from traits NPP and FP for cross $1 \times 9$ and from traits LP, FP and DPM for cross $4 \times 5$. Also, the positive dominance effect of SY was from traits NPP, LP, FP and DPM for crosses $5 \times 7$ and $5 \times 8$ (Table 5). In earlier studies, (Lefort-Buson and Dattee 1982; Downey and Rimer 1993; Thakur and Sagwal 1997) significant dominance effects for seed yield and yield components in B. napus and other Brassica species have been reported. 
Predicted dominance effects of seed yield (SY) and contributed dominance effects (\%) of agronomic trait to SY for F1 crosses in repressed

\begin{tabular}{|c|c|c|c|c|c|c|c|c|}
\hline \multirow{2}{*}{ Crosses } & \multicolumn{7}{|c|}{ Contributed dominance effects of taits to $S Y$} & \multirow{2}{*}{ sY } \\
\hline & NPP & HFB & HFP & LP & SD & FP & DPM & \\
\hline $1 \approx 2$ & $-0.1082^{\prime \prime}$ & $-0.1158^{11}$ & $-0.1191^{\text {the }}$ & $-0.0982^{\prime \prime}$ & $-0.0939^{4}$ & $-0.1119^{\prime \prime}$ & -0.0451 & $-109.52^{n t}$ \\
\hline $1 \times 3$ & $0.1696^{* 1}$ & $0.2239^{\prime *}$ & $0.2208^{n+1}$ & $0.2790^{* *}$ & $0.1703^{* *}$ & $0.2141^{\prime *}$ & $0.2365^{n *}$ & $214.88^{\prime \prime}$ \\
\hline $1 \times 4$ & $-0.2097^{* 1}$ & $-0.2921^{1 *}$ & $-0.3027^{4+1}$ & $-0.2602^{* *}$ & $-0.2679^{71}$ & $-0.2610^{17 *}$ & $-0.2382^{\prime \prime \prime}$ & $-269.98 *$ \\
\hline $1 \times 5$ & $0.2558^{* 1}$ & $0.2695^{* *}$ & $0.2793^{4 *}$ & $0.2947^{* *}$ & $0.2932^{* *}$ & $0.2697^{4 *}$ & $0.2422^{\prime \prime}$ & $294.87^{* 1}$ \\
\hline $1 \times 6$ & 0.0146 & $0.0952^{* *}$ & $0.0883^{*}$ & 0.0418 & 0.0378 & 0.0257 & $0.0731^{*}$ & 27.50 \\
\hline $1 \times 7$ & -0.0619 & $-0.1372^{\prime *}$ & $-0.1505^{4 *}$ & $-0.1545^{* *}$ & $-0.1117^{*}$ & $-0.1154^{*}$ & -0.0640 & $-127.45^{* 1}$ \\
\hline $1 \times 8$ & $-0.3927^{m}$ & $-0.3097^{=1}$ & $-0.3439^{4 *}$ & $-0.3738^{\prime *}$ & $-0.3646^{17}$ & $-0.3726^{4 *}$ & $-0.3134^{\prime \prime}$ & $-365.73^{\prime \prime}$ \\
\hline $1 \times 9$ & $0.0653^{\prime \prime}$ & -0.0128 & 0.0035 & 0.0262 & 0.0486 & $0.0643^{\prime \prime}$ & -0.0560 & $49.35^{\circ}$ \\
\hline $2 \times 3$ & $0.1158^{* "}$ & $0.0598^{\circ}$ & $0.0402^{n+*}$ & $0.1145^{* *}$ & $0.1301^{\circ}$ & $0.1473^{\prime \prime}$ & $0.1046^{\circ}$ & $111.47^{* 1}$ \\
\hline $2 \times 4$ & -0.0402 & $-0.0632^{\prime \prime}$ & $-0.0551^{*}$ & -0.0432 & -0.0339 & -0.0390 & -00430 & $-38.68^{\circ}$ \\
\hline $2 \times 5$ & -0.0447 & 0.0273 & $0.0715^{*}$ & $-0.1207^{* *}$ & -0.0563 & $-0.0832^{\prime \prime}$ & -0.0583 & $-60.71^{\prime}$ \\
\hline $2 \times 6$ & $-0.2645^{m}$ & $-0.2772^{* *}$ & $-0.2833^{4 *}$ & $-0.2335^{* *}$ & $-0.2149^{1 *}$ & $-0.23066^{4 *}$ & $-0.3254^{\prime \prime}$ & $-232.27^{\prime \prime}$ \\
\hline $2 \times 7$ & 0.0367 & $0.1765^{n *}$ & $0.1563^{4 *}$ & 0.0530 & 0.0391 & 0.0330 & $00898^{\prime \prime}$ & 47.27 \\
\hline $2 \times 8$ & $-0.1491^{\prime \prime}$ & $-0.0901^{*}$ & $-0.1099^{-4}$ & $-0.0561^{*}$ & $-0.1995^{\prime \prime}$ & $-0.1101^{\prime \prime}$ & $-0.2426^{\prime \prime}$ & $-129.54^{* 1}$ \\
\hline $2 \times 9$ & $0.3004^{* "}$ & $0.2047^{1 "}$ & $0.2060^{10 *}$ & $0.2771^{* *}$ & $0.2638^{* 1}$ & $0.2205^{4 *}$ & $0.2881^{\prime \prime}$ & $277.54^{" *}$ \\
\hline $3 \times 4$ & $-0.0714^{*}$ & -0.0276 & -0.0383 & $-0.0622^{\circ}$ & -0.0257 & $-0.0814^{\prime \prime}$ & -0.0148 & $-43.69^{\circ}$ \\
\hline $3 \times 5$ & -0.0559 & $0.0718^{\prime \prime}$ & 0.0269 & $-0.0677^{\prime \prime}$ & $-0.1040^{\circ}$ & -0.0154 & -0.0662 & $-90.40^{\circ}$ \\
\hline $3 \times 6$ & $0.2938^{" \prime}$ & $0.1752^{\circ *}$ & $0.2248^{n+*}$ & $0.2916^{\prime *}$ & $0.2469^{\circ "}$ & $0.2898^{4 *}$ & $0.2795^{\circ *}$ & $297.62^{\circ}$ \\
\hline $3 \times 7$ & $-0.1142^{\prime \prime}$ & $-0.0888^{\prime \prime}$ & $-0.0626^{\prime \prime}$ & $-0.1454^{\prime *}$ & $-0.1160^{\circ}$ & $-0.1007^{\prime \prime}$ & $-0.1743^{\prime \prime}$ & $-124.54^{\prime \prime}$ \\
\hline $3 \times 8$ & -0.0276 & $-0.1041^{n *}$ & $-0.0450^{\circ}$ & $-0.0623^{\prime \prime}$ & -0.0304 & -0.0114 & $-00824^{\circ}$ & $-36.75^{\prime}$ \\
\hline $3 \times 9$ & $-0.1823^{\prime \prime}$ & $-0.2046^{11}$ & $-0.1957^{4+1}$ & $-0.2230^{\prime \prime}$ & $-0.1798^{1 "}$ & $-0.1698^{\prime \prime}$ & $-0.1182^{\prime \prime \prime}$ & $-192.38^{\prime \prime}$ \\
\hline $4 \times 5$ & 0.0143 & 0.0293 & 0.0363 & $0.1030^{\prime *}$ & $0.0666^{*}$ & $0.0627^{*}$ & $0.1109^{* *}$ & $76.42^{\circ}$ \\
\hline $4 \times 6$ & $0.2283^{*}$ & $0.2102^{\prime *}$ & $0.1828^{* *}$ & $0.2135^{* *}$ & 0.1973 & $0.208 \mathrm{~s}^{* *}$ & $0.1500^{\circ "}$ & $203.48^{* 1}$ \\
\hline $4 \times 7$ & $-0.3458^{* 1}$ & $-0.2760^{\circ *}$ & $-0.3278^{t+1}$ & $-0.3544^{\prime *}$ & $-0.3884^{\prime \prime}$ & $-0.3582^{\prime \prime}$ & $-0.4219^{\prime \prime}$ & $-374.80^{\circ 1}$ \\
\hline $4 \times 8$ & $0.3233^{\mathrm{n}}$ & $0.2714^{14}$ & $0.2883^{14}$ & $0.3338^{14}$ & $0.3463^{17}$ & $0.3424^{4 *}$ & $0.3295^{11}$ & $349.77^{\prime \prime}$ \\
\hline $4 \times 9$ & $0.2022^{2 .}$ & $0.3009^{* *}$ & $0.2742^{* *+}$ & $0.1668^{17}$ & $0.1847^{* *}$ & $0.1810^{1 *}$ & $0.1537^{* *}$ & $175.79^{\circ "}$ \\
\hline $5 \times 6$ & 0.0195 & 0.0177 & -0.0030 & 0.0376 & -0.0193 & -0.0211 & 0.0047 & -9.33 \\
\hline $5 \times 7$ & $0.2457^{\mathrm{m}}$ & 0.1825 & $0.2024^{n=}$ & $0.2745^{1 *}$ & $0.2858^{\prime \prime}$ & $0.3094^{41}$ & $0.1270^{\prime \prime}$ & $285.28^{\prime \prime}$ \\
\hline $5 \times 8$ & $0.1594^{="}$ & 0.0231 & 0.0095 & $0.1016^{\prime *}$ & $0.1188^{*}$ & $0.1326^{\prime \prime}$ & $0.1159^{\circ \prime}$ & $110.41^{* *}$ \\
\hline $5 \times 9$ & $-0.1671^{m "}$ & $-0.1285^{\prime \prime}$ & $-0.1421^{4 *}$ & $-0.1426^{\prime *}$ & $-0.1484^{\circ}$ & $-0.1688^{4 *}$ & -0.0467 & $-149.21^{\prime \prime}$ \\
\hline $6 \times 7$ & $0.2388^{\circ "}$ & $0.2193^{\prime \prime}$ & $0.2380^{\circ+1}$ & $0.2152^{\prime *}$ & $0.2393^{\prime \prime}$ & $0.2327^{4 *}$ & $0.1923^{\prime \prime}$ & $229.38^{\prime \prime}$ \\
\hline $6 \times 8$ & 0.0419 & $0.1046^{\prime \prime}$ & $0.0907^{*}$ & $0.0580^{\circ}$ & $0.1002^{\circ}$ & $0.0953^{*}$ & $0.0972^{\circ}$ & $77.00^{\circ}$ \\
\hline $6 \times 9$ & $0.0632^{m "}$ & $0.1945^{\prime \prime}$ & $0.1749^{n *}$ & $0.0920^{\circ}$ & $0.0925^{\circ}$ & $0.0662^{\prime \prime}$ & $0.1113^{\prime \prime}$ & $77.74^{\circ}$ \\
\hline $7 \times 8$ & $0.5289^{=1}$ & $0.4928^{\prime \prime}$ & $0.4935^{* *+}$ & $0.5045^{\circ}$ & $0.5364^{\prime \prime}$ & $0.5185^{4 *}$ & $0.5199^{\prime \prime}$ & $531.35^{* 1}$ \\
\hline $7 \times 9$ & -0.0171 & $-0.0521^{\prime \prime}$ & -0.0213 & -0.0121 & 0.0136 & $-0.0467^{\prime \prime}$ & 0.0453 & -2.29 \\
\hline $8 \times 9$ & $-0.2126^{m "}$ & $-0.0983^{1}$ & $-0.1239^{4 *}$ & $-0.1794^{1 *}$ & $-0.2567^{* 4}$ & $-0.21288^{4 *}$ & $-0.1645^{11}$ & $-235.22^{\prime \prime}$ \\
\hline
\end{tabular}

$* *$ and $*$ respectively, significant at $1 \%$ and $5 \%$ probability level

There were negative dominance effects of seed yield (SY) for 16 combinations consist on $1 \times 2,1 \times 4,1 \times 7,1 \times 8,2 \times 4,2 \times 5,2 \times 6,2 \times 8,3 \times$ $4,3 \times 5,3 \times 7,3 \times 7,3 \times 8,3 \times 9,4 \times 7,5 \times 9$ and $8 \times 9$ crosses (Table 5). Similar to positive additive effects, the negative dominance effect of SY was resulted from different traits for different crosses but most of the positive 
dominance effect of SY was resulted mainly from all traits. For most of the $\mathrm{F}_{1}$ crosses presented in Table 5, there were the highest contributed dominance effects due to LP and FP among the seven agronomic traits. Only for four of 35 crosses, which had no significant dominance effects of SY, HFB, HFP and DPM for crosses $1 \times 6$ and $2 \times 7$ had also the contribution to dominance effects of SY among the agronomic traits investigated.

Although seed yield and other related traits of rapeseed was influenced by environmental effects and sampling errors due to the significant residual variance, the genetic variance due to $V_{D \times Y}$ (dominance $\times$ year interaction) accounted for relatively more variation. Hence these traits were mainly influenced by dominant and dominance $\times$ year interaction, with $\mathrm{V}_{\mathrm{D} \times \mathrm{Y}}$ effect the most important player. The dominance $\times$ year interaction provides a measure of the stability of the mean effects of dominance and non-allelic interaction over years, its variance ratio in the present instance suggesting moderate instability (Allard, 1956). Therefore, in the genetic control of seed yield and most traits which studied in this investigation, non-allelic interaction of a complementary type was inferred, and it proved to be quite stable in different environments. Dominance relationships in the genetic control of traits appeared to shift with environmental changes.

\section{DISCUSSION}

Dominance genetic effects are important in formulating breeding strategies in most cases. In the present investigation, dominance $\times$ year interaction genetic effects played a major role in the inheritance of seven traits and seed yield of rapeseed. Additive genetic effects also affected some traits such as NPP, but were of little importance due to its smaller effects and significant interaction with year. The additive effects, on the contrary, did not interact with years and had smaller effect on the traits. The major role of dominance genetic effects and dominance $\times$ year interaction effects in controlling most traits and seed yield suggests that selection in early segregating generations should not be effective in bringing about desirable changes in these traits. The involvement of nonadditive genetic effects in the inheritance of yield component traits in rapeseed was previously reported by Brandle and McVetty (1989), Singh et al. (1995), Rameah et al. (2003) and Marjanovic-Jeromela et al. (2008).

The response of a genotype to environmental changes is determined by phenotypic plasticity which is shown by the genotype when its phenotype of a given character is able to be altered by environmental influences (Allard and Bradshaw 1964; Bradshaw 1965). This concept can be applied to genetic effects consist on additive and dominance effects. The null hypothesis of no dominance $x$ year interactions was rejected for certain differences between the dominance effects (Table 1). The tests for qualitative interactions revealed that the 
interactions genetic effects with the environment were quite different. Witcombe and Whittington (1971) found in rapeseed that when the physical effect of environmental factors on germination of seeds was unlike, as between temperature and water potential, every genotype had different phenotypic plasticities of germination speed and each plasticities was specific to a particular environmental factor. If genotype $\times$ environment interactions depend on the physical nature of the environments, separate analyses corresponding to each of the environmental factors to be tested might be useful for studying the phenotypic plasticity (Miura et al., 1988).

Conditional analysis was developed for analyzing conditional variance components and conditional genetic effects (Zhu, 1995; Atchley and Zhu, 1997). This method can be used for evaluating more genetic variation and pure genetic effects of target trait such as seed yield conditional on given variables such as yield components (Xiao et al., 2007). Thus, the contribution of one agronomic trait to certain seed yield of leaves can be measured by conditional analysis. It can uncover not only the contributed genetic variance but also the contributed genetic effects for individual parent or F1 cross due to traits. Seed yield is an important target for oilseed production and it was observed that all seven traits and specially NPP, FP and DPM had significant effects on seed yield. Similar results could also he obtained analyzing partial correlation of all traits. Therefore number of pods per plant should be given more attention as the main traits of selection. Similar results have been reported by other researchers who suggested NPP as the one of the most important trait in determine of rapeseed yield (Li et al., 2001; Zhang and Zhu, 2006).

Although certain interpretations of the diallel mating design may be prone to error, this procedure has proved useful in providing basic information about the genetic relationships among the rapeseed cultivars selected for this investigation. This information should be effectively exploited in selecting specific crosses for more exhaustive testing of genetic mechanisms controlling seed yield. For detecting additive, dominance and their interaction with environment effects, Zhu (1994) developed an additive-dominance genetic model that requires data from parental, and F1 generations. The use of such models may help improve the rapeseed breeder's understanding of the underlying gene action, and provide a better estimate of the heritability of a given trait. Analyses of variation in segregating generations of certain crosses from the diallel has provided more detailed information on the genetic control of seed yield. The diallel analysis should also prove useful in screening cultivars for use as parents in a breeding program aimed at modifying improvement seed yield through selection.

Finally according to additive-dominance genetic model and conditional genetic effects, the genotypes Talaye proved good general combiner for seed yield improvement due to all measured traits. Flowing to this cultivar, Orient can be used for a genetic material in rapeseed breeding programs. Also, crosses $4 \times 8$ (Orient $\times$ 
Talaye), $7 \times 8$ (Opera $\times$ Talaye) were found the best specific combiner for all the studied traits flowed by $3 \times 6$ (SLM046 $\times$ Zarfam) and $1 \times 5$ (Fornax $\times$ Colvert) crosses. This outcome could be a good indicator to identify the most promising genotypes to be utilized either as F1 hybrids or as a resource population for further selection in rapeseed improvement. For making reliable recommendations, it is essential to investigate the relationship among these traits, other traits which are not shown in this paper and oil content for rapeseed. This topic will be considered in detail in a subsequent paper because both oil content and seed yield are the important properties for food and industrial use of rapeseed.

\section{ACKNOWLEDGMENTS}

Thanks to Prof. Jun Zhu for his helpful comments and providing QGAStation software used for this research. We are grateful Seed and Plant Improvement Institute (SPII) for providing us experiment materials.

\section{REFERENCES}

Abderrahmane A., Zhu J. 2001. Diallel analysis for inbred lines involving genotype $\times$ environment interaction effects on additive-dominance genetic model. J. Biol. Sci. 1: 704-707.

Allard R.W. 1956. The analysis of genetic-environment interactions by means of diallel crosses. Genetics, 41: 305-318.

Allard R.W., Bradshaw A.D. 1964. Implications of genotype $\times$ environmental interactions in applied plant breeding. Crop Sci. 4: 503-508.

Atchley W.R., Zhu J. 1997. Developmental quantitative genetics, conditional epigenetic variability and growth in mice. Genetics, 147: 765-776.

Xiao B.G., Zhu J., Lu X.P., Bai Y.F., Li Y.P. 2007. Analysis on genetic contribution of agronomic traits to total sugar in flue-cured tobacco (Nicotiana tabacum L.). Field Crops Res. 102: 98-103.

Bradshaw A.D. 1965. Evolutionary significance of phenotypic plasticity in plants. Advan. Genet. 13: 115-155.

Brandle J.K., Mcvetty P.B.E. 1989. Heterosis and combining ability in hybrids derived from oilseed rape cultivars and inbred lines. Crop Sci. 29: 1191-1195.

Chen J.G., Zhu J., Pan Q.M. 1997. Analysis of genetic covariance between quality traits and agronomic characters in indica-japonic crosses of rice (Oryza sativa L.). J. Hubei Univ. 19: 278-282.

Cockerham C.C. 1980. Random and fixed effects in plant genetics. Theor. Appl. Genet. 56: 119-131.

Cooper M., Byth D.E. 1996. Understanding plant adaptation to achieve systematic applied crop improvementA fundamental challenge. In M. Cooper and G.L. Hammer (ed.) Plant adaptation and crop improvement. CAB International, Wallingford, UK.

Dehghani D., Omidi H., Sabaghnia N. 2008. Graphic analysis of trait relations of canola (Brassica napus L.) using biplot method. Agron. J. 100: 760-764.

Downey R.K., Rimer S.R. 1993. Agronomic Improvement in Oilseed Brassicas. Advan. Agron. 50: 1-150.

Gardner C.O., Eberhart S.A. 1966. Analysis and interpretation of the variety cross diallel and related populations. Biometrics, 22: 439-452.

Griffing B. (1956. Concept of general and specific combining ability in relation to diallel systems. Aust. J. Biol. Sci. 9: 463-493.

Hallauer A.R, Miranda J.B. 1981. Quantitative genetics in maize breeding. Iowa States University Press, Ames, IA.

Han IQ, Liu HL, 1993. Principal component an1ysis for main agronomic and quality characters of hybrids in rapeseed (Brassica napus L.). J. Huazhong Agric. Univ. 12: 42-43.

Hartley H.D, Rao J.N.K. 1967. Maximum-likelihood estimation for the mixed analysis of variance model. Biometrika, 54: 93-108.

Hayman B.I. 1954. The theory and analysis of diallel crosses. Genetics, 39: 789-809.

Ivanovska S., Stojkovski C., Dimov Z., Marjanovic-Jeromela A., Jankulovska M., Jankuloski L. 2007. 
Interrelationship between yield and yield related traits of spring canola (Brassica napus L.) genotypes. Genetika, 39: 325-332.

Lefort-Buson M., Dattee Y. 1985. Study of heterosis in winter oilseed rape (Brassica napus L.). II. Genetic structure of the population. Agronomie, 5: 201-207.

Lefort-Buson M., Dattee Y. 1982. Genetic study of some agronomic characters in winter oilseed rape (Brassica napus L.) II. genetic parameters. Agronomie, 2: 323-332

Li A.M., Thing Y., Hui F.H. 2001. Analysis of the characters of hybrid rapeseed combination and major breeding goals. J. Anhui Agric. Sci. 29: 308-310.

Marinkovic R., Marjanovic-Jeromela A. 2004. Combining ability in some varietes of winter oil rape (Brassica napus L.). Biotech. Biotech. Equip. 18: 110-114.

Marjanovic-Jeromela A., Marinkovi R., Mijic A., Zdunic Z., Ivanovska S., Jankulovska M. 2008. Correlation and path analysis of quantitative traits in winter rapeseed (Brassica napus L.). Agricul. Cons. Scien.73: 13-18.

Marjanovic-Jeromela A., Marinkovic R., Mijic A., Jankulovska M., Zdunic Z. 2007. Interrelationship between oil yield and other quantitative traits in rapeseed (Brassica napus L.). J. Cent. Euro. Agric. 8: 165-170.

Miller R.G. 1974. The jackknife- a review. Biometrika, 61: 115.

Miura H., Saitoh K., Tsuda C. 1988. Diallel analysis of genotype-environment interactions for the speed and uniformity of germination in rustica tobacco. Jap. J. Breed. 38: 17-26.

Olsson G. 1960. Some relations between number of seeds per pod, seed size and oil content and the effects of selection for these haracters in Brassica and Sinapsis. Hereditas, 46: 27-70.

Ozer H., Oral E., Dogru U. 1999. Relationship between yield and yield components on currently improved spring rapeseed cultivars. Turkish Journal Agriculture and Forestry, 23: 603-607.

Pospisil M., Mustapic Z. 1995. Evaluacija novih OO-kultivara uljane repice. Sjemenarstvo, 12: 273-282.

Rameah V., Rezai A., Saeidi G. 2003. Estimation of genetic parameters for yield, yield components and glucosinolate in rapeseed (Brassica napus L.). J. Agric. Sci. Tech. 5: 143-151.

Rao C.R. 1970. Estimation of heteroscedastic variances in linear models. J. Amer. Statis. Assoc. 65: 161172.

Rao C.R. 1971. Estimation of variance and covariance components MINQUE theory. J. Multiv. Anal.1: 257-275.

Richards R.A., Thurling N. 1979. Genetic analysis of drought stress response in rapeseed (B. campestris L. and B. napus L.) II. Yield improvement and the application of selection indices. Euphytica, 28: 169- 177.

SAS Inc, 1996. SAS/STAT user's guide. Version 6.12. SAS Institute Inc, Cary, NC. USA.

Shi C.H., Zhang H.Z., Wu J.G., Li C.T., Ren Y.L. 2003. Genetic and genotype x environment interaction effects analysis for erucic acid content in rapeseed (Brassica napus L). Euphytica, 130: 249-254.

Shi C.H., Wu J.G., Lou X.B., Zhu J., Wu P. 2002. Genetic analysis of transparency and chalkiness area at different filling stages of rice (Oryza sativa L.). Field Crops Res. 76: 1-9.

Tak G.M. 1976. Correlation and path-coefficient analysis of yield component in the three forms of Brassica campestris. Crop Improv. 3: 50-52.

Thakur H.L., Sagwal J.C. 1997. Heterosis and combining ability in oilseed rape (Brassica napus L.). Indian J. Genet. 57: 163-167.

Witcombe J.R., Whittington W.J. 1971. a Study of the genotype by environmental interaction shown by germinating seeds of Brassica napus. Heredity, 26: 397-411.

Wu J.G., Shi C.H., Zhang H.Z. 2006. Partitioning genetic effects due to embryo, cytoplasm and maternal parent for oil content in oilseed rape (Brassica napus L.). Genet. Mol. Biol. 29: 533-538.

Yan W., Kang M.S. 2003. GGE biplot analysis: a graphical tool for breeders, geneticists, and agronomists. CRC Press, Boca Raton, FL.

Zhang G., Zhu W. 2006. Genetic analyses of agronomic and seed quality traits of synthetic oilseed Brassica napus produced from interspecific hybridization of B. campetris and B. oleracesea. J. Genet. 85: 45-51.

Zhu J. 1992. Mixed model approaches for estimating genetic variances and covariances. J. Biomath. 7: 1-11.

Zhu J. 1993. Mixed model approaches for estimating covariances between two traits with unequal design matrices. J. Biomath. 8: 24-30.

Zhu J. 1994. General genetic models and new analysis methods for quantitative traits. J. Zhejiang Agric. Univ. 20: 551-559.

Zhu J. 1995. Analysis of conditional effects and variance components in developmental genetics. Genetics, 141: $1633-1639$.

Zhu J., Weir B.S. 1994a. Analysis of cytoplasmic and maternal effects: I. a genetic model for diploid plant seeds and animals. Theor. Appl. Genet. 89: 153-159.

Zhu J., Weir B.S. 1994b. Analysis of cytoplasmic and maternal effects: II. genetic models for triploid endosperms. Theor. Appl. Genet. 89: 160-166.

Zhu J., Weir B.S. 1998. Mixed model approaches for genetic analysis of quantitative traits. In Advanced Topics in Biomathematics: Procceedings of International Conference on Mathematical Biology. pp:321-330. 
Edited by L. S. Chen, S. G. Ruan, and J. Zhu, World Scientific Publishing Co., Singapore.

Zhu J., Weir B.S. 1996. Mixed model approaches for diallel analysis based on a bio-model. Genet. Res. 68: 233-240.

Singh D., Malik V., Singh H. 1995. Gene Action of Seed Yield and Other Desirable Characters in Oilseed Rape (Brassica napus L.). Ann. Biol. Luddhiana, 11: 94-97.

Yadav V.P., Singh H. 1996. Morpho-physiological determinates of yield under water stress conditions in Indian Mustard. Acta Horticulture, 407: 155-160.

Zhu J. (1996. Analytic methods for seed models with genotype $\times$ environment interactions. Chin. J. Genet. 23: $11-22$.

Zhu J., Ji D.F., Xu F.H. 1993. A genetic approach for analyzing inter-cultivar heterosis in crops. Chin. J. Genet. 20: $183-191$.

Zhang S., Hu J., Zhang C.F., Guan Y.J., Zhang Y. 2007. Genetic analysis of fruit shape traits at different maturation stages in sponge gourd. J. Zhejiang Univ. Sci. 8: 338-344. 